\title{
TEORI EKONOMI DAVID RICARDO, THOMAS ROBERT MALTUS, DAN JEAN BAPTIS SAY
}

Alyaghina Ismirana 90100118115

\section{A. Teori David Ricardo (1772-1823)}

David Richardo merupakan seorang praktisi yang berasal dari keluarga pedagang sebagai stock broker, Bukunya adalah Principles of Political Economy and Taxation terbit pada tahun 1817. Ricardo penganut Laissez Faire, dan mengembangkan dasar teori nilai yang terkenal dengan labor theory of value. Pergaulannya sangat luas, dan kenal dengan James Mill, Jeremy Bentham, Jean Baptiste Say. David Ricardo sebagai ahli ekonomi politik Inggris yang lahir pada tahun 1772. Ricardo adalah seorang pemikir yang paling menonjol di antara segenap pakar Mahzab klasik. Ia sangat terkenal karena kecermatan berpikir, metode

pendekatannya hampir seluruhnya deduktif. David Ricardo telah mengembangkan pemikiran-pemikiran Adam Smith secara lebih terjabar dan juga lebih sistematis. Teori yang dikembangkan oleh David Ricardo menyangkut empat kelompok kesenjangan yaitu:

1) teori tentang nilai dan harga barang dan yang berkaitan dengannya itu,

2) teori tentang distribusi pendapatan sebagai pembagian hasil dari seluruh produksi dan disajikan sebagai teori upah, teori sewa tanah, teori bunga, dan laba,

3) teori tentang perdagangan internasional, dan

4) teori tentang akumulasi dan perkembangan ekonomi.

Teori Ricardo yang terkenal adalah tentang teori keunggulan komparatif. Perdagangan tergantung pada keunggulan komparatif atau efisiensi relatif daripada keunggulan absolut. Negara akan cenderung menjual barangnya yang relatif lebih efisien dalam produksinya. Sehingga melalui spesialisasi, setiap negara akan memperoleh keuntungan dari perdagangan luar negeri. Melalui teori keunggulan 
komparatif, Ricardo menyatakan bahwa sebuah negara harus memusatkan kegiatan perekonomiannya pada industri yang menjadi unggulannya dan paling kompetitif secara internasional, serta melakukan kegiatan perdagangan dengan negara lain untuk memperoleh barang yang tidak diproduksi secara nasional.

Ricardo juga mengemukakan teori distribusi pendapatan yang mengandung tiga elemen yaitu:

1. Teori sewa. Teori sewa yang dikemukakan Ricardo mengacu pada teori Malthus, yaitu teori sewa diferensial. Sewa berasal dari perbedaan kesuburan tanah. Ketika tanah semakin menurun kesuburannya, maka sewa diferensial akan naik.

2. Teori tentang upah. Upah pekerja menurut Ricardo tergantung pada keperluan subsisten yaitu kebutuhan minimum yang diperlukan pekerja agar dapat bertahan hidup. Kebutuhan minimum yang dimaksud oleh Ricardo adalah kebutuhan yang tergantung pada lingkungan dan adat istiadat. Jika standar hidup meningkat, maka upah yang dibayarkan kepada pekerja juga meningkat.

3. Teori laba. Keuntungan atau laba adalah residu setelah kaum kapitalis membayar upah pekerja mereka dan membayar sewa kepada pemilik tanah (Pressman, 2000).

Pemikiran Ricardo yang relevan dengan perekonomian di Indonesia adalah :

1. Spesialisasi yang dimiliki oleh industri-industri di Indonesia sehingga menjadi industri yang unggul dan kompetitif dalam perdagangan internasional dan Indonesia melakukan perdagangan internasional dengan negara lain untuk barang-barang yang tidak diproduksi di dalam negri, sehingga keuntungan yang diperoleh dari perdagangan internasional ini akan tercipta.

2. Keikutsertaan Indonesia pada perdagangan bebas, yang bertujuan mengurangi halangan dalam melakukan perdagangan antar negara. Indonesia menjadi anggota AFTA, MEA, APEC.

3. Penentuan upah minimum yang didasarkan pada Kebutuhan Hidup Layak (KHL) dengan memperhatikan produktivitas dan pertumbuhan ekonomi. Upah 
minimum yang dikenal di Indonesia adalah Upah minimum Provinsi (UMP) dan Upah Minimum Kota/Kabupaten (UMK).

\section{B. Thomas Robert Maltus (1766-1834)}

Thomas Robert Malthus dilahirkan tahun 1766, dekat Dorking di Surrey, Inggris, dia bersekolah di Jesus College di Universitas Cambridge selaku mahasiswa yang cemerlang. Pada tahun 1805, Malthus menjadi menjadi seorang profesor pertama dalam bidang ekonomi politik di East India Company Colledge di Haileybury, Hertfordshire, Inggris.

Buku-bukunya tentang ekonomi politik adalah : principles of Political Economy (1820) dan Definitions of Political Economy (1827), An Inquiry into the Nature and Progress of Rent (1815), dan bukunya yang terkenal adalah Essay on Principle of Population as it Affects the Future Improvement of Society (1798). Dari buku ini terlihat bahwa Malthus merupakan salah seorang pengikut Adam Smith yang memiliki sikap pesimis terhadap masa depan manusia.

Pola dasar pemikiran Malthus dan kerangka analisisnya ialah menyangkut teori mengenai sewa tanah dan teori mengenai penduduk. Dalam teorinya Malthus menggambarkan bahwa tanah sebagai salah satu sumber produksi utama tetap jumlahnya, terutama untuk pertanian karena semakin banyak yang digunakan oleh pabrik-pabrik, jalan, atau untuk perumahan dan kelahiran yang tidak terkontrol menyebabkan penduduk bertambah menurut deret ukur padahal persediaan bahan makanan bertambah secara deret hitung. Artinya, pertambahan penduduk jauh lebih cepat dari pertambahan bahan makanan. Akibatnya suatu saat nanti akan terjadi perbedaan yang besar antara jumlah penduduk dengan ketersediaan bahan makanan, sehingga bahaya kelaparan akan mengancam penduduk Bumi. Apalagi Malthus juga berpendapat bahwa bahan makanan sangat penting untuk kehidupan manusia sementara nafsu manusia tidak dapat ditahan, termasuk nafsu biologis untuk 
menghasilkan keturunan. Oleh karena itu, maka Malthus meramal bahwa suatu ketika akan terjadi malapetaka (disaster) yang akan menimpa umat manusia.

Seperti yang terjadi pada saat ini Covid-19 sebagai penyebab penyakit Korona yang banyak menghilangkan nyawa manusia, menjadi menarik bila dikaitkan dengan Teori Malthus. Yang menarik, dalam Teori Malthus, ada yang disebut dengan preventive checks dan positif checks sebagai faktor pencegah yang dapat mengurangi kegoncangan dan kepincangan terhadap perbandingan jumlah penduduk dengan ketersediaan bahan makanan. Sederhananya, preventive dan posititive checks inilah yang akan menghambat pertambahan penduduk di mana pandemik Covid-19 termasuk salah satu di antaranya.

Dalam bukunya Priciples of Population ia menguraikan bahwa satu-satunya cara untuk menghindar dari malapetaka tersebut adalah dengan melakukan control atas pertumbuhan penduduk.

\section{Jean Baptiste Say (1767-1832)}

Jean Baptiste Say adalah seorang tokoh ekonomi penting Prancis yang lahir tahun 1767 tepat Sembilan tahun sebelum The Wealth of Nation dicetak. Seperti halnya Ricardo, Say juga berlatar belakang seorang pengusaha. Say sangat mengagumi Adam Smith, Say juga sangat berjasa dalam melakukan kodifikasi pemikiran Smith dan dirangkum dalam bukunya "Traite d'Economie Politique" pada tahun 1803, dan mendukung paham Laissez Faire.

Pada usia 32 tahun Say menjadi anggota Tribunat (Seorang perwira Romawi kuno dipilih untuk melindungi hak-hak mereka dari tindakan sewenang-wenang dari para hakim bangsawan) Napoleon. Namun Napoleon diktator yang haus kekuasaan yang menentang kebijakan Say 'Laissez Faire Say' dan mengeluarkan Say dari tibunat setelah terbit karyanya yang berjudul Treatise on political economi pada tahun 1806. Napoleon bahkan melarang penyebaran buku Say karena dalam buku itu Say mengecam kebijakan Napoleon. 
Kontribusi Say yang paling besar terhadap aliran Klasik ialah pemikirannya ( yang dikenal dengan Say's Law) yang menyatakan setiap penawaran akan menciptakan permintaannya sendiri (supply creates its own demand), ini merupakan hukum yang paling terkenal dari Say. Asumsinya adalah bahwa nilai produksi selalu sama dengan pendapatan. Setiap ada produksi selalu ada pendapatan, yang besarnya persis sama dengan nilai produksi tadi. Jadi, dalam keadaan seimbang produksi cenderung menciptakan permintaannya sendiri atas barang yang bersangkutan.

Say juga menciptakan istilah entrepreuner yang diterjemahkan menjadi "petualang", yang menununjukan petualangan komersil atau petualangan kapitalis, yaitu orang yang menggabungkan input kapital, tenaga kerja dan pengetahuan untuk menciptakan profit.

J.B say merupakan seorang pengusaha karena itu ia mengungkapkan bahwa peran pengusaha dalam perekonomian itu sangant penting. Entrepreuner ini juga dimasukan sebagai unsur yang penting dalam model ekonominya. Dalam bukunya ia menjabarkan makna panjang dari entrepreuner yang intinya adalah seseorang harus mempunyai ilmu seni untuk mengawasi dan administrasi. Dan dia hrus tahu bahwa selalu ada kemungkinan gagal. Tetapi bila sukses para kelompok ini akan mendapatkan kekayaan yang sangat banyak. 


\section{DAFTAR PUSTAKA}

Atmanti, H. D. (2017). Kajian Teori Pemikiran Ekonomi Mazhab Klasik dan Relevansinya pada Perekonomian Indonesia. JEB17: Jurnal Ekonomi dan Bisnis,2(02).

Deliarnov. (2014). Perkembangan Pemikiran Ekonomi. Edisi Ketiga. Jakarta: Rajawali Pers.

Faruq, U. A., \& Mulyanto, E. (2017). Sejarah Teori-Teori Ekonomi.

Fawzi, N. I., \& Husna, V. N. (2021, April). PEMANFAATAN INFORMASI GEOSPASIAL UNTUK KETAHANAN PANGAN SAAT PANDEMI COVID-19. In Seminar Nasional Geomatika (pp. 1-10).

FIRMANSYAH, F. (2007). Sejarah pemikiran ekonomi.

Ma'ruf, A., \& Wihastuti, L. (2008). Pertumbuhan ekonomi indonesia: determinan dan prospeknya. Jurnal Ekonomi \& Studi Pembangunan, 9(1), 44-55.

Muna, T. I., \& Qomar, M. N. (2020). Relevansi Teori Scarcity Robert Malthus Dalam Persepektif Ekonomi Syariah. SERAMBI: Jurnal Ekonomi Manajemen dan Bisnis Islam, 2(1), 1-14.

Purba, B., Sudarmanto, E., Syafii, A., Nugraha, N. A., Zaman, N., Ahdiyat, M., \& Umarama, A. (2020). Ekonomi Politik: Teori dan Pemikiran. Yayasan Kita Menulis.

Saidy, E. N. (2018). Uang dalam Tinjauan Ekonomi Islam. Laa Maisyir: Jurnal Ekonomi Islam, 4(2).

Suprapto, M. S. (2021). Perkembangan Pemikiran Ekonomi dan Kontroversi.

Subair, S. (2018). RELEVANSI TEORI MALTHUS DALAM DISKURSUS KEPENDUDUKAN KONTEMPORER. DIALEKTIKA, 9(2). 
